\title{
New-Onset Palmoplantar Psoriasis During Treatment of Active Ankylosing Spondylitis with TNF-alpha Blocking Agent Adalimumab
}

\author{
TNF-alfa Bloke Edici Ajan Adalimumabla Yürütülen Aktif Ankilozan Spondilit \\ Tedavisi Sırasında Meydana Gelen Yeni Başlangıçlı Palmoplantar Psoriyazis
}

Özgür AKGÜL, Mustafa ÇALIŞ, Salih ÖZGÖÇMEN

Division of Rheumatology, Department of Pysical Medicine and Rehabilitation, Medical Faculty of Erciyes University, Kayseri, Turkey

Tumor necrosis factor (TNF) antagonists are available for treatment of the common rheumatic diseases rheumatoid arthritis (RA), ankylosing spondylitis (AS), psoriatic arthritis (PsA) as well as Crohn's disease and psoriasis. ${ }^{[1]}$ Unexpected side effects of TNF antagonists increasingly reported in the literature are cutaneous adverse reactions which include skin rash, urticaria, hyperhidrosis, seborrheic dermatitis, alopecia, rosacea injection site reactions, non-melanoma skin cancer, lupus-like syndrome, erythema multiforme, Steven's Johnson syndrome and toxic epidermal necrolysis or psoriatic skin lesions. ${ }^{[2-4]}$ Also, worsening of psoriatic skin lesions due to anti-TNF treatment has been reported in patients with PsA. ${ }^{[5]}$ Here we report on a patient with AS who developed palmopustular psoriasis during successful treatment with adalimumab.

\section{CASE REPORT}

A 33-year-old man with a 13-year history of AS started on anti-TNF, adalimumab $40 \mathrm{mg}$ every other week because of inadequate response to previous diseasemodifying anti-rheumatic drugs administered for the previous 12 months. He had a good response to anti-TNF treatment and no longer complained of morning stiffness and had a sustained score of less than 3 on the Bath Ankylosing Spondylitis Disease Activity Index (BASDAI). He suddenly developed pustular and erythematous skin lesions on his palms and soles at the $12^{\text {th }}$ month of adalimumab treatment (figure 1). There was no history of previous skin lesions or allergic diseases and no family history of psoriasis. He had normal acute phase response and no clinical or laboratory evidence for infections including Chlamydia. The patient was referred for dermatology consultation, and a punch biopsy of the lesions demonstrated psoriasiform epidermal hyperplasia with acanthosis, hyperkeratosis and parakeratosis and intraepidermal pustulosis. A topical steroid was administered for the palmoplantar pustular psoriasis lesions which responded well and disappeared completely within a couple of weeks. In a follow up after two weeks, palmoplantar pustular psoriasis completely resolved with local treatments. Adalimumab was discontinued and the patient followed up with a meloxicam $15 \mathrm{mg}$ daily treatment.

Development or worsening of psoriasis with TNF antagonists can occur at any time from days to years after the initiation of treatment. ${ }^{[6,7]}$ Skin lesions have been reported in all diseases treated with TNF antagonists including psoriasis, rheumatoid arthritis, ankylosing spondylitis, psoriatic arthritis, inflammatory bowel disease and juvenile idiopathic arthritis. $^{[6]}$ Theoretically, several immunologic pathways may induce this reaction. The most frequent type of psoriasis is palmopustular psoriasis. ${ }^{[8]}$ 

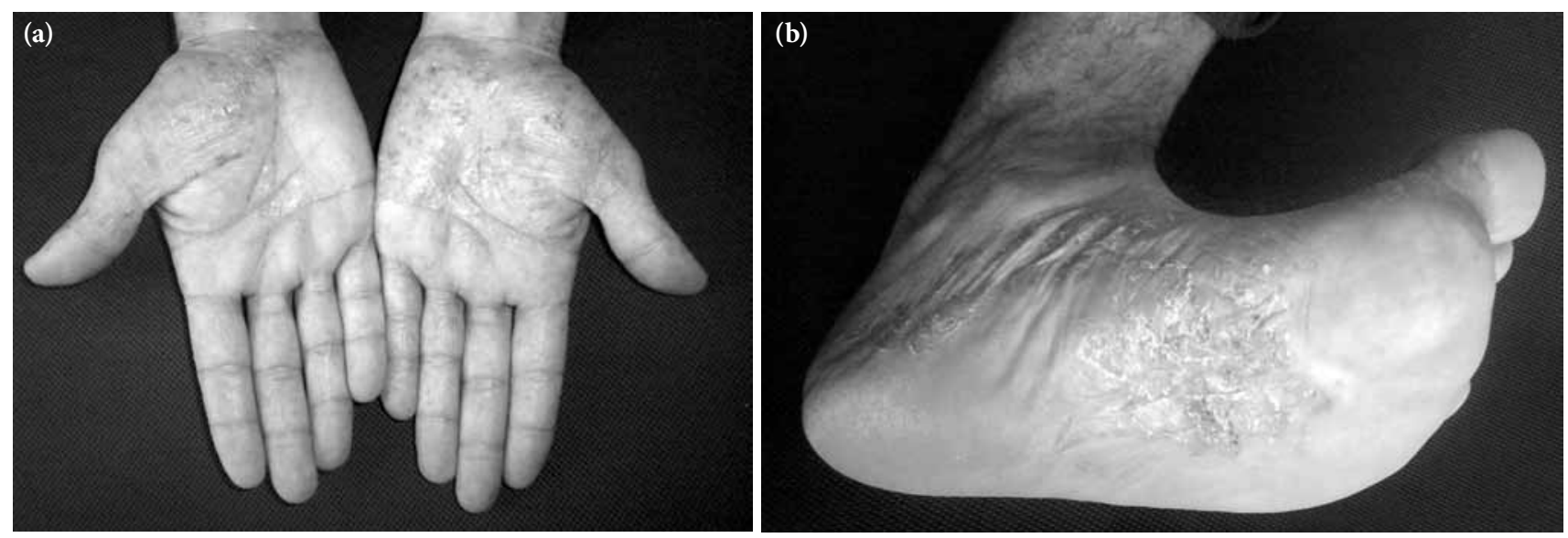

Figure 1. (a) Palmar and (b) plantar erythematous papulopustular lesions with scaling, hyperkeratosis and desquamation.

Although the exact mechanism is unknown, it has been postulated that chronic anti-TNF suppression could be associated with a cytokine imbalance between TNF-alpha and interferon (IFN)-alpha. Plasmacytoid dendritic cells (PDCs) and their production of IFNalpha appear to be the key factors in the induction of psoriasis in these patients. ${ }^{[6,9]}$ The inhibition of TNFalpha may result in increased IFN-alpha expression and homing of type I T helper (Th1) cells to the skin. This is a probable mechanism for the development of paradoxical psoriasis in patients undergoing TNF antagonist therapy. ${ }^{[9,10]}$

Induction or exacerbation of psoriasis with the use of anti-TNF therapeutic agents has been rarely reported in patients with AS (particularly after adalimumab treatment). The majority was reported after treatment with infliximab. ${ }^{[7]}$ This is not surprising since infliximab is the first drug available in the market and is approved for the treatment of AS, while adalimumab is a newer drug in the market with respect to infliximab. Severe psoriatic or palmoplantar lesions developed after anti-TNF treatments may necessitate the discontinuation of the TNF drug and local, systemic treatment of psoriasis. However, as in our case, palmoplantar lesions may respond well to topical treatment and the discontinuation of anti-TNF treatment was required.

\section{Declaration of conflicting interests}

The authors declared no conflicts of interest with respect to the authorship and/or publication of this article.

\section{Funding}

The authors received no financial support for the research and/or authorship of this article.

\section{REFERENCES}

1. Takahashi H, Hashimoto Y, Ishida-Yamamoto A, Ashida T, Kohgo Y, Iizuka H. Psoriasiform and pustular eruption induced by infliximab. J Dermatol 2007;34:468-72.

2. Lee HH, Song IH, Friedrich M, Gauliard A, Detert J, Röwert J, et al. Cutaneous side-effects in patients with rheumatic diseases during application of tumour necrosis factor-alpha antagonists. Br J Dermatol 2007;156:486-91.

3. Kerbleski JF, Gottlieb AB. Dermatological complications and safety of anti-TNF treatments. Gut 2009;58:1033-9.

4. Exarchou SA, Voulgari PV, Markatseli TE, Zioga A, Drosos AA. Immune-mediated skin lesions in patients treated with anti-tumour necrosis factor alpha inhibitors. Scand J Rheumatol 2009;38:328-31.

5. Borrás-Blasco J, Gracia-Perez A, Nuñez-Cornejo C, Rosique-Robles JD, Mateu-Puchades A, Casterá MD, et al. Exacerbation of psoriatic skin lesions in a patient with psoriatic arthritis receiving adalimumab. J Clin Pharm Ther 2008;33:321-5.

6. Collamer AN, Guerrero KT, Henning JS, Battafarano DF. Psoriatic skin lesions induced by tumor necrosis factor antagonist therapy: a literature review and potential mechanisms of action. Arthritis Rheum 2008;59:996-1001.

7. Ko JM, Gottlieb AB, Kerbleski JF. Induction and exacerbation of psoriasis with TNF-blockade therapy: a review and analysis of 127 cases. J Dermatolog Treat 2009;20:100-8.

8. Fiorino G, Allez M, Malesci A, Danese S. Review article: anti TNF-alpha induced psoriasis in patients with inflammatory bowel disease. Aliment Pharmacol Ther 2009;29:921-7.

9. de Gannes GC, Ghoreishi M, Pope J, Russell A, Bell D, Adams S, et al. Psoriasis and pustular dermatitis triggered by TNF-\{alpha\} inhibitors in patients with rheumatologic conditions. Arch Dermatol 2007;143:223-31.

10. Aeberli D, Seitz M, Jüni P, Villiger PM. Increase of peripheral CXCR3 positive T lymphocytes upon treatment of RA patients with TNF-alpha inhibitors. Rheumatology (Oxford) 2005;44:172-5. 